\title{
Creativity in Children with Attention Déficit Hyperactivity Disorder (ADHD)
}

\author{
Gracia Gonzalez-Carpioㄴ, Juan Pedro Serrano², Marta Nieto ${ }^{3}$ \\ ${ }^{1}$ Child and Youth Mental Health Unit, Castilla La Mancha University Hospital, Toledo, Spain \\ ${ }^{2}$ Department of Psychology, School of Medicine Castilla-La Mancha, Albacete, Spain \\ ${ }^{3}$ Department of Psychology, School of Nursing Castilla-La Mancha, Cuenca, Spain \\ Email: JuanPedro.Serrano@uclm.es
}

How to cite this paper: Gonzalez-Carpio, G., Serrano, J. P., \& Nieto, M. (2017). Creativity in Children with Attention Déficit Hyperactivity Disorder (ADHD). Psychology, 8, 319-334.

https://doi.org/10.4236/psych.2017.83019

Received: December 14, 2016

Accepted: February 10, 2017

Published: February 13, 2017

Copyright (c) 2017 by authors and Scientific Research Publishing Inc. This work is licensed under the Creative Commons Attribution International License (CC BY 4.0).

http://creativecommons.org/licenses/by/4.0/

(c) (i) Open Access

\begin{abstract}
Research about creativity in ADHD children is very limited and has shown discordant results. Some features of cognitive functioning in ADHD, such as scattered attention, difficulty suppressing brain activity of the default neural network, inefficiency to inhibit irrelevant stimuli that access consciousness, or common markers-based genetics, are at the base of the connection between ADHD and creativity. The aim of this study is to explore whether the ADHD children are more creative and obtain better results in the divergent tasks traditionally considered as measures of creativity regarding children control. Method: The sample comprised 68 children, aged 8 to 13 years. A group of 34 children diagnosed with $\mathrm{ADHD}(\mathrm{M}$ age $10.5, \mathrm{SD}=1.6$ ) was compared to a control group of 34 without $\mathrm{ADHD}(\mathrm{M}$ age $=10.8, \mathrm{SD}=1.7)$. None were under pharmacological treatment. The children were assessed using the Torrance Tests of Creative Thinking Figurative (TTCT). Results: ADHD children showed better results in some areas of creativity, showing higher scores in Fluency, with a greater number of responses, Originality, with a greater number of unusual or unconventional responses, together with higher scores in Creative strengths, which include measures for movement or action, emotional expressiveness, story-telling articulateness, unusual visualization, humor or fantasy. Partial $\eta^{2}$ effect sizes ranged from 0.19 to 0.34 . As a consequence of those partial superior resultados, the ADHD children show a higher global creativity index than the control group. Conclusions: Our results suggest that children diagnosed with ADHD are more creative, than typically developing children, not in all evaluated areas but in some of them. This finding could provide guidance for the use of more effective assessments and interventions to promote this positive quality in children with ADHD.
\end{abstract}

\section{Keywords}

ADHD, Children, Creativity, Torrance Tests of Creative Thinking 
Figurative (TTCT)

\section{Introduction}

Whether there is a greater disposition for creativity in children with attention deficit hyperactivity disorder (ADHD) than in typically developing children remains inconclusive (Paek, Abudulla, \& Cramond, 2016). Yet, the hypothesis is attractive insofar as it could highlight positive characteristics of children with ADHD. According to the Diagnostic and Statistical Manual of Mental Disorders (DSM-5) from the American Psychiatric Association (2013), ADHD is characterized by the appearance of three core symptoms: inattention, hyperactivity and impulsiveness. It is described as a persistent pattern of personal functioning that prevents typical normalized development or daily activities and negatively interferes with school activities. ADHD is one of the most frequently diagnosed disorders in the child population. A meta-analysis conducted by Polanczyk, Lima, Horta, Biederman, \& Rohde (2007) initially estimated a prevalence of $5.3 \%$ among individuals under the age of 18. Drawing on a review of 175 studies on ADHD prevalence, a work by Thomas, Sanders, Doust, Beller, \& Glasziou (2015) estimated an overall pooled estimate of $7.2 \%$ in the whole child population.

The most direct consequence of this disorder is the impact on different aspects of personal and social relationships (Barkley et al., 2002). Broadly speaking, in comparison with typically developing children, ADHD children are more likely to drop out of the educational system, less likely to complete a university degree, more likely to work in lower class employment, more likely to be involved in antisocial activities and high-risk situations, and frequently present difficulties and conflicts, in relationships with peers and families. In a longitudinal study (Holbrook et al., 2014), over a 6-year period, children ADHD were aged from 5 to 13 years. They found that inattention symptoms were maintained until adolescence, and the symptoms of hyperactivity impulsivity decreased with age. According to Biederman, Petty, Clarke, Lomedico, \& Faraone (2011), in their 11 years of follow-up of children with ADHD, these difficulties tend to appear in early childhood and persist into adulthood. Their study shows that once diagnosed, in different degrees and in different areas, the disorder continues to affect $78 \%$ of subjects with ADHD in adulthood, with variations according to clinical or subclinical symptoms.

Creativity is regarded as an individual's ability to generate new ideas and potentially useful solutions in different situations (Sternberg \& Lubart, 1996). Despite multiple theories of creativity (Runco, 2014; Sternberg, Kaufman, \& Pretz, 2002), a consensus appears to exist that novelty and utility are two key factors in the creative process (Plucker, Beggheto, \& Dow, 2004; Runco, 2007; Sternberg \& Lubart, 1999). The novelty or originality of a response is defined in statistical terms by its rarity or singularity; utility refers to the capacity to achieve an objective in a certain context. For Simonton (2004), the concept of creativity requires 
the willingness to think outside the usual norms, to find novelty and the unconventional along with the ability to be open to experience. It is for this reason that the creative people have as characteristics such us unfocused attention, divergent thought, and behaviors oriented to the independence and nonconformity. This form of functioning, can also be presented in ADHD people. Cramond (1994a) warned about possible overlapping functional traits of creative children and ADHD children. Sternberg \& Kaufman (2010) warned about the risk of not identifying creative people hidden by their ADHD. The relationship between $\mathrm{ADHD}$ and creativity is based on possible overlapping forms of functioning, similar cognitive or neurological characteristics.

It should also be considered that intellectual ability is one of the factors that may be affecting creativity, according to (Jauk, Benedek, \& Neubauer, 2014) depends on the intelligence the conversion of skills or knowledge gained in remarkable creative achievements.

In the case of children, there is an added difficulty in evaluating creativity, the tests measure their creative potential, since recognized creative products may need time, experience and a level of knowledge not reached in childhood making it necessary to evaluate their potential creativity (Beghetto \& Kaufman, 2007). Consistent with this consensus on the nature of creativity, one of the most representative and widely used divergent thinking tests to measure creative potential is the Torrance Tests of Creative Thinking (TTCT, Torrance, 1974; 2008). It measures different creativity dimensions that are defined in Table 1.

Table 1. TTCT figurative Torrance subtests.

\begin{tabular}{|c|c|c|}
\hline $\begin{array}{l}\text { Dimension } \\
\text { Creativity }\end{array}$ & Definition & $\begin{array}{l}\text { Score range } \\
\text { Min.-max }\end{array}$ \\
\hline Fluency & The number of drawings completed. & $40-153$ \\
\hline Originality & The statistical infrequency and unusualness of the response. & $40-154$ \\
\hline Elaboration & $\begin{array}{l}\text { The individual's ability to develop, extend and elaborate } \\
\text { upon ideas: the number of additional details used in } \\
\text { developing the response beyond what would be strictly } \\
\text { necessary for the basic response. }\end{array}$ & $40-160$ \\
\hline $\begin{array}{l}\text { Abstractness } \\
\text { Titles }\end{array}$ & $\begin{array}{l}\text { The ability to produce good titles using synthesizing and } \\
\text { organizing processes. The ability to capture the essence. Such a } \\
\text { title enables the viewer to see the picture more deeply and richly. }\end{array}$ & $40-160$ \\
\hline Resistance & A creative person's ability to stay open and tolerate ambiguity & \\
\hline $\begin{array}{l}\text { Premature } \\
\text { Closure }\end{array}$ & $\begin{array}{l}\text { long enough to generate novel ideas and perform the mental } \\
\text { leap that makes possible original ideas. }\end{array}$ & $40-160$ \\
\hline $\begin{array}{l}13 \text { Creative } \\
\text { Strengths }\end{array}$ & $\begin{array}{l}\text { Emotional expressiveness, storytelling articulateness (context, } \\
\text { environment), movement or action, expressiveness of titles, } \\
\text { synthesis of incomplete figures, synthesis of line or circles, } \\
\text { unusual visualization, internal visualization, extending } \\
\text { boundaries, humor, richness of imagery, } \\
\text { colorfulness of imagery, fantasy. }\end{array}$ & $1-26$ \\
\hline
\end{tabular}




\subsection{Neurological Hypothesis}

The common nexus between ADHD and creativity is based on forms of cognitive functioning, such as a delay in cortical maturation affecting two aspects, the maturation process trajectory and final cortical thickness reached. In children with ADHD this process can be delayed by two or more years, compared to the typical development expected for children without ADHD, as documented by authors (El-Sayed, Larsson, Persson, Santosh, \& Rydelius, 2003; Shaw et al., 2007). This delay, from the point of view of Thompson-Schill, Ramscar \& Chrysikou (2009), would offer an evolutionary advantage since this immaturity in the prefrontal control, where the executive functions are located, regulates the thought and the behavior and favors a flexible way of thinking that is not conditioned by expectations or beliefs. Uncontrolled cognition allows us to approach new solutions or creative ideas without limitations.

Regarding the way to confront the creative task, there are similarities of functioning between ADHD and creative, both groups show difficulties for the deactivation of the default neural network (DNN) to tasks that require more mental effort, which leads to the maintenance of a dispersed, unfocused mental state (Mattfeld et al., 2014, Sonuga-Barke \& Castellanos, 2007, Uddin et al., 2008).

At the genetic level the common nexus between the creative and the ADHD group is based on that they can share some genetic markers, all of them related to dopaminergic neurotransmission. One of the most supportive hypotheses is the presence of the DRD4-7R gene (Auerbach, Benjamin, Faroy, Geller, \& Ebstein, 2001, Dietrich \& Kanso, 2010, Munafò, Yalcin, Willis-Owen, \& Flint, 2008), known as the search for novelty gene and at the same time associated with a greater dispersion and attentional amplitude, present in ADHD, make essential traits for divergent thinking emerge, (Auerbach et al., 2001). This behavior can already be identified in very young children, around one year of age, when they perform tasks of structured play and tasks of information processing that require a certain degree of attention, this form of carrying operation with more dispersed attention and preference for novelty was observed with greater intensity in children DRD4-7R gene compared to children without the 7R allele (Auerbach et al., 2001).

\subsection{Experimental Studies with ADHD Children}

Other authors have found evidence for widened attentional focus which would enhance creative processes in ADHD children. Shaw \& Brown $(1990,1991)$ demonstrated that ADHD children used more diverse nonverbal information and were able to focus attention on different stimuli in their immediate environment, resulting in higher figural creativity. Other authors suggest the inability of ADHD children to screen out irrelevant stimuli when performing a task (latent inhibition) results in the availability of more stimuli for use in creative processes (Carson, Peterson, \& Higgins 2003; Pritchard, Healey, \& Neumann, 2006).

A number of studies have addressed the relationship between ADHD and creativity, with a variety of designs and findings. Healey \& Rucklidge (2006) 
found that $40 \%$ of creative children showed elevated levels of ADHD symptomatology, although none met the clinical diagnostic criteria for ADHD. Using Torrance's Figurative TTCT, Cramond (1994b) compared a group of children with ADHD and a group of creative children, finding that $26 \%$ of creative children had ADHD trends measured on the SNAP-IV scale (Swanson, 2003) and that $36 \%$ of children with ADHD scored high on creativity.

In the study conducted by Abraham, Windmann, Siefen, Daum, \& Güntürkün (2006) on creative cognition in ADHD, adolescents ADHD outperformed healthy and matched control participants in the task of giving new uses to a toy. Their poor inhibitory control or being easily distractible make them better able to override the restrictive influence imposed by relevant or relevant knowledge when it comes to being creative. And they can expand conceptual structures to include unusual or new associations. Taylor (2006) found that children with ADHD had high levels of fluidity and flexibility, understanding that the latter was the ability to generate varied ideas. According to White \& Shah (2006), young adults with ADHD were more likely to find creative solutions than those who did not, showing a preference for generating ideas. However, they did not perform better than the control group when "correct" responses were required (White \& Shah, 2011). In contrast to the above, other authors (Healey \& Rucklidge, 2005; Sang, Yu, Zhang, \& Yu, 2002) did not find that children with ADHD were more creative than those who did not.

One of the potential methodological problems in comparing the different studies is the lack of control of the medication status of research participants, since pharmacological treatment can improve attention deficit symptoms (Pliszka, 2007; Swanson, Cantwell, Lerner, McBurnett, \& Hanna, 1991) but can also decrease curiosity, exploratory effort and cognitive flexibility (Hansen \& Hansen, 2006). High doses can produce excessive focusing and clinical symptoms of perseveration (Tannock \& Schachar, 1992), findings suggest that methylphenidate (MPH) may reduce cognitive flexibility temporarily in some ADHD children, and as recently demonstrated, can decrease fluency, originality and number of creative strengths and the overall index of creativity, measured by the TTCTFigurative (González-Carpio \& Serrano, 2016). Other authors have found no relationship between medication and excessive focusing and widened attentional focus (Douglas, Barr, Desilets, \& Sherman, 1995; Funk, Chessare, Weaver, \& Exley, 1993).

Limited research with children with ADHD shows that there is a controversy surrounding the greater or lesser degree of creativity in people with ADHD, especially in the child population, the aim of this study was to analyze the possible differences in creativity in a group of ADHD children compared to a control group, none of whom were under pharmacological treatment. Our hypothesis was that children with ADHD would perform better on creativity than the controls.

Creativity was operationalized using the Torrance Tests of Creative Thinking Figurative (Torrance, 1998, 2008) scored for each of the five dimensions of crea- 
tivity (Fluency, Originality, Elaboration, Abstractness of Titles and Resistance to Closure), the sum of Creative Strengths, which measure characteristics of creative personality, and the Creativity Index, which combines the five dimensions and the creative strengths score.

\section{Methods}

\subsection{Participants}

\subsubsection{Participants with ADHD}

A total of 34 children with ADHD participated in the study, all outpatients recruited from the Child and Youth Mental Health Unit (SMIJ) at the Virgen de la Salud Hospital, Toledo (Spain). The diagnosis was given by experienced clinical psychologists, following the DSM-5 criteria. The assessment used a children's mental health interview with parents and children covering all developmental aspects, symptoms over the last six months and current symptoms, and information obtained from teachers at the children's schools. Teachers completed the SNAP-IV scales (Swanson, 2003). Children with an ADHD diagnosis were included if within the age range 8 to 13 years and willing to take part in the study.

All ADHD children taking stimulant medication, or any other type of medication, at the time of the study or during the previous year, were excluded, as were those presenting associated disorders, anxiety disorders, mood state disorders, and child or adolescent onset antisocial behavior and autism spectrum disorders. We also excluded children with low intellectual capacity, neurological disorders, or uncorrected visual or hearing problems. Out of 34 children belonging to the ADHD group 16 were ADHD with no other diagnoses added and the remaining 18 were ADHD with one or more associated disorders, including: four cases of oppositional defiant disorder; (F91.8), two cases of enuresis, in the younger age group (F98.1), 12 had reading-writing disorders, (F81.0) along with learning difficulties, (F81) and because of these difficulties, seven had also repeating a school year.

\subsubsection{Participants without ADHD}

A total of 34 children in a similar age range of 8 to 13 years were selected for the control group. All the participants were below the threshold for ADHD diagnosis, confirmed by experienced clinical psychologists. Clinical interviews were conducted with children and parents and information was collected from teachers by use of the SANP-IV scales. The children's mental health history was also consulted. The control group was recruited from patients attending the SMIJ for various reasons, specifically.

The difficulties of this group of children who attended the consultation were: six children had unspecified learning disorders (F81.9), six children had repeated courses due to poor school performance, (Z55.3), a child had somnambulism , (F51.3), 10 children with problems related to family breakup by separation, (Z63.5), five children with problems related to adjustment to vital transitions, (Z60.0), two cases of bullying, (Z55.4), a child with problems related to inade- 
quate social skills, (Z73.4) and three cases without pathology. We established two groups matched by age, gender and place of origin. Selection was conducted simultaneously with the ADHD group. The same exclusion criteria were used as for the ADHD participants. Table 1 shows the characteristics of the ADHD and control group.

\subsection{Procedure}

Participants were recruited from children referred to the Child and Youth Mental Health Unit (USMI) by the pediatric neurology service, the pediatrician or the family physician at the local health centers. For your evaluation, either for suspected ADHD or other problems. Subsequently, the SNAP-IV scales performed by the teacher were analyzed and punctuated, and the clinical diagnostic interview was carried out to complete the history of children's mental health.

Once the information was verified from the three points of view the school, family and clinical diagnosis was established by clinical psychologists. After the evaluation, children and families were voluntarily invited to participate in the study, following the inclusion criteria/Exclusion mentioned above. Once consent was given, the K-BIT test battery was administered to measure intellectual ability and in a subsequent session the TTCT-Figurative creativity test was administered. The tests were performed by a single investigator, previously trained to administer and record the test, which facilitated consistent data collection. Each session lasted between 60 and 90 minutes, depending on the willingness of each child to collaborate. The TTCT-figurative was administered in a relaxed manner appropriately. The children were asked to draw pictures, following the instructions in the test manual. All procedures followed were in accordance with the ethical standards of the committee responsible for human experimentation (institutional and national) and with the Declaration of Helsinki of 1975, revised in 2000 (Manzini, 2000).

\subsection{Measures}

ADHD symptom rating scale. The SNAP-IV Rating Scale Revised IV-R (Swanson, 2003) is a scale with nine Likert-type items (range 0 - 3) for the attention subscale and nine items for the hyperactivity-impulsivity subscale. The scale is completed by teachers, who rate the presence of the symptoms. Scores represent the average rating per item on each subscale and the total scale. Percentile 95 is used as the cut-off point for normality. Cut-off points for the teacher rating: 1) For attention deficit: $2.56,2$ ) For hyperactivity/impulsivity: 1.78, and 3) 2.00 for attention deficit and hyperactivity/impulsivity.

Intellectual functions. The Kaufman Brief Intelligence Test (K-BIT) (Cordero \& Calonge, 2000) is a general intelligence measure consisting of two subtests: vocabulary (expressive vocabulary and definitions) and matrices. The scores obtained have a mean of 100 and a standard deviation of 15 , for both the vocabulary and matrices subtests and the compound intelligence quotient.

Measure of creativity. Torrance Tests of Creative Thinking-Figural (TTCT), 
parallel forms A and B (Torrance, 2008), translated into Spanish, consist of three subtests or games: 1) constructing a drawing, 2) completing a drawing, and 3) making different drawing using two parallel lines. Five dimensions comprising creativity are evaluated. Table 1 defines the five subscales or dimensions of creativity and the thirteen creative strengths. A total Creativity Index is derived from the five dimensions and the Creative strengths. The battery enables conversion of test scores to percentiles with a mean of 100 and standard deviation of 20 . Torrance (1998) reported reliability ranging from 0.89 to 0.94 , and Torrance (1990) reported that reliability was over 0.90. According to the study by Kim, Cramond, \& Bandalos (2004), the alpha coefficient for consistency was 0.79 .

\subsection{Data Analysis}

Scores were distributed normally to groups, as assessed by the Shapiro-Wilk normality $(p>0.05)$. There was homogeneity of variances, as assessed by Levene's test of homogeneity of variance $(p>0.05)$. Box plots revealed an atypical value but this was not omitted from the study as it did not affect the results. One-factor ANOVAs were conducted to compare ADHD and control group scores on each dimension of creativity and the total score. Effect sizes were calculated for all the comparisons of means, following Cohen (1988), using eta partial squared $\left(\eta^{2} \mathrm{p}\right)$ to more accurately determine the magnitude of the difference (Castro \& Martini, 2014). An alpha of 0.05 was set for the statistical analysis. SPSS version 20.0 was used for data analysis.

No significant differences were found between the ADHD children and controls for age, gender or general intellectual capacity. As expected, the children without ADHD obtained significantly lower scores and did not meet the cut-off points on the SNAP-IV questionnaire to assess ADHD symptoms.

No significant differences were found between the ADHD children and controls for age, gender or general intellectual capacity. As expected, the children without ADHD obtained significantly lower scores and did not meet the cut-off points on the SNAP-IV questionnaire to assess ADHD symptoms.

Regarding the ADHD group, no significant differences were found between the two subtypes predominantly inattention or hyperactivity-impulsivity, regarding scores on the SNAP-IV scale, according $\mathrm{t}(33)-1.372, p=0.179 \mathrm{~d}=$ 0.23 . So, they have not been able to differentiate specific subtypes, being grouped for subsequent analysis. The control group, also not found significant differences $\mathrm{t}(33)-1.630, p=0.113, \mathrm{~d}=0.28$.

A one-factor ANOVA was conducted to determine whether there were differences between the children with $\mathrm{ADHD}$ and the controls for the levels of fluency, originality, elaboration, abstractness of titles, resistance to premature closure, creative strengths and the overall creativity index. Analysis of each variable showed significant differences for fluency, originality, creative strengths and the overall creativity index with a large effect size. No significant differences were found between the children with ADHD and the controls for elaboration, abstractness of titles or resistance to premature change (Table 2), with effect size. 
Table 2. Characteristics of the ADHD and control group samples. Data refer to mean and standard deviation.

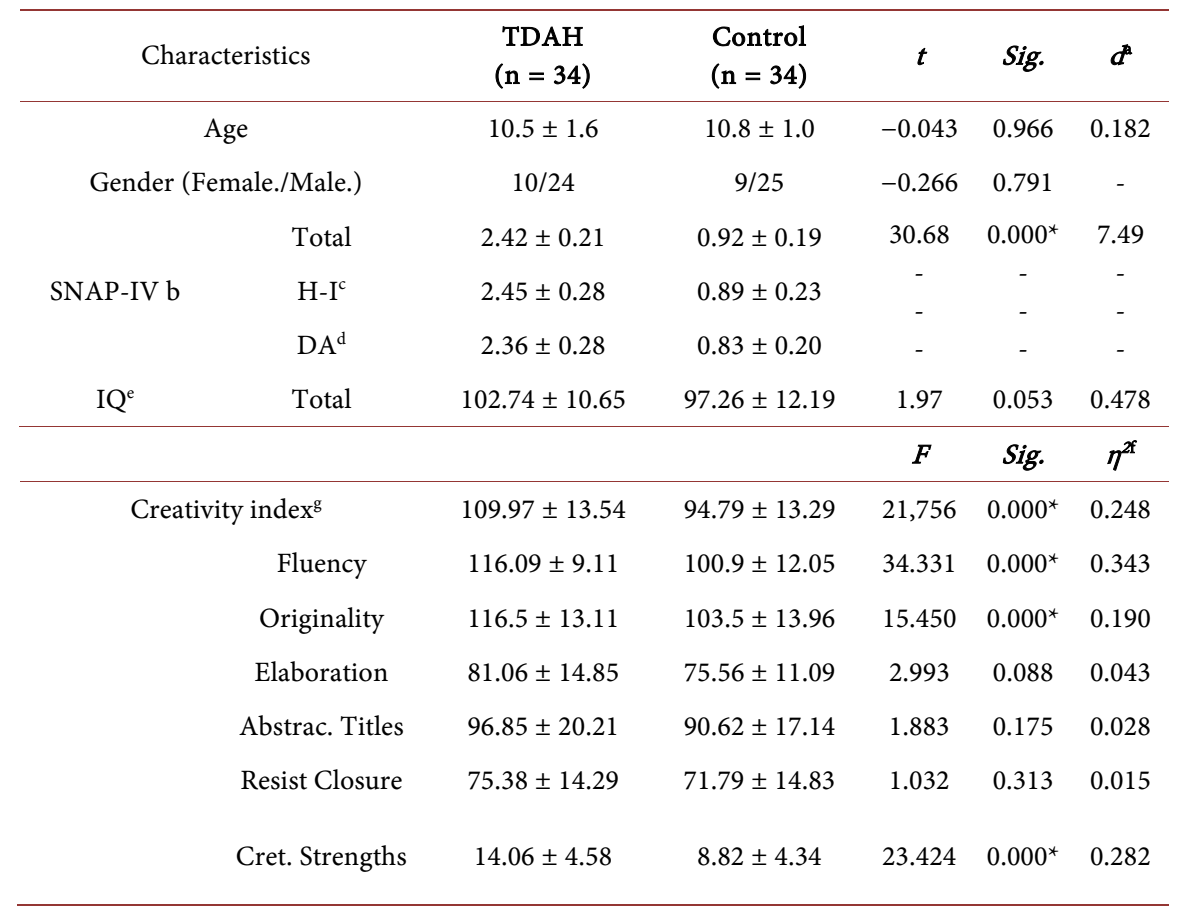

Note. ${ }^{a}$ Cohen's effect size d: insignificant $<0.20$, small 0.20 a 0.50 , medium 0.50 a 0.80 and $>0.80$ large. ${ }^{b} S N A P-I V, A D H D$ symptom rating scale. ${ }^{c} \mathrm{H}-\mathrm{I}$ hyperactivity-impulsivity. ${ }^{\mathrm{d} D A}$ inattention. ${ }^{\mathrm{e}}$ Intelligence quotient on K-BIT. ${ }^{\mathrm{f}}$ Effect size $\eta 2$ partial Cohen.: $<0.01$ small, 0.06 medium y $>$ a 0.14 large. ${ }^{\mathrm{g}}$ Creativity index TTCT Figurative Torrance. ${ }^{\star}$ Level of significance $p<0.05$.

\section{Discussion}

The aim of our study was to verify whether ADHD children are more creative than typically developing children. Defining creativity as a form of divergent thinking, we used the TTCT-Figurative as our assessment instrument. Our results indicate that ADHD children score higher than controls on the Fluency subtest, a task consisting of generating as many different drawings as possible from an initial neutral stimulus. Similarly, Shaw \& Brown (1999) found that ADHD children generated a greater number of imaginative responses, especially when aroused, and Abraham et al. (2006) found that ADHD children performed better on tasks where they were given a limited time to generate as many novel ideas for toys as possible.

Our results also show that children with higher fluency scores also score higher on Originality of ideas. This observation coincides with Kim et al. (2004) and Torrance \& Safter (1999), who found that children who produce a large number of ideas are also more likely to generate original ideas. According to Krumm, Lemos, \& Filippetti (2014), fluency and originality form part of the innovation factor reflects the different ways of approaching creative problem solving. In their view, the most innovative children prefer to obtain creative results through "outside the box" thinking, which could be at the core of ADHD children's functioning.

Children with ADHD also scored higher on Creative strengths, giving more 
responses implying unusual visualization of perspective, representing internal content or visualization from unexpected angles, as well as figures, objects or nature in movement. This is in line with the findings of other studies such as that by Sahib (2012), in a group of $40 \mathrm{ADHD}$ children of 5 and 6 primary grades evaluated by TTCT figurative, compared to the control group, in which ADHD group exhibited more movement responses and a greater number of imaginative stories than controls, although both groups provided the same number of fantasy responses.

In our study, no significant differences were found between ADHD children and controls for the other dimensions of Elaboration, Abstractness of titles and Resistance to premature closure.

So, in the overall Creativity Index that combines the scores of the five subtests and is a global assessment of creative potential, the children with ADHD scored significantly higher than control children.

In the present study, $21 \%$ of children with ADHD scored at or above $70 \%$ for the overall creativity index, according to the age-adjusted scale for a general population. This percentage suggests that there are more highly creative children in the ADHD group than in a general population. The percentage of highly creative children in the ADHD group in the present study was not as high as that obtained by Fugate, Zentall, \& Gentry (2013), who, using the TTCT-figurative, found that $41 \%$ of their ADHD group scored O above the 90th percentile in the overall creativity index. In their ADHD group, however, $53 \%$ reached or over the 70th percentile in intellectual ability, which may have been a determining factor in the results (Shaw \& Brown, 1990, 1991). With a sample of 34 children with ADHD, Cramond (1994b) found that 50\% scored above the 70th percentile in TCTT-Figurative, thus exhibiting high intellectual and creative abilities.

Although there is no total agreement on the threshold hypothesis, it establishes outside IQ range 80 - 120 intellectual capacity becomes independent of creativity. The relationship between creativity and intellectual ability suggests the need for further research into this relationship, including other factors such as motivation or personality factors.

In conclusion, our results show that children with $\mathrm{ADHD}$ aged 8 to 13 exhibited greater general and specific creative potential in certain areas (fluency, originality and creative strengths) but presented no differences from controls in other areas (elaboration, abstractness of titles and resistance to premature change). It would be of great interest to know if this creative potential is converted into creative achievements in the future.

\subsection{Implications}

The correct identification of ADHD children to their full potential would favor their integration and adaptation to the school system and if the existence of greater creative ability in ADHD children was revealed as a trend, it could help in identifying positive aspects of these ADHD children. This would make it possible to improve the traditional evaluation systems that usually only focus on 
the deficits presented.

This would allow us to have a more complete view of these children and potentially, this could contribute to better designs of treatments that enhance their creativity, even though ADHD does not possess this characteristic uniformly and above the rest of the population. First, at the educational level, intervention plans can be designed to improve their already traditional academic performance deficiency. But they also improve the vision that parents and partners have of these children usually impaired by behavior problems.

Secondly, the diagnosis would also be improved, since as Cramond (1994a) points out. The consequences of not identifying creative children due to their altered and unconventional behavior may affect their use in all areas. But creativity can also be hidden in ADHD, due to only considering the negative part of the disorder, so a misdiagnosis and the use of a pharmacological treatment must be performed from both perceptive.

The potentialities of this study about children with ADHD were carried out in a trend to develop an innovative intervention.

Based on this assumption the line of research of the present work has sought to provide a further advance in the knowledge of the functioning of a group of ADHD children, for future designs of effective treatments and educational interventions. If, as we have seen, creativity in some areas offers some advantage for ADHD, it could be evaluated and used as compensatory features of its habitual difficulties.

\subsection{Limitations and Future Research}

The size of the sample may make it difficult to obtain significant results, but it has been compensated by obtaining a size effect of the differences obtained from moderate to large, which has allowed us to generalize results. The sample size may also affect the originality subtest, as its score is based on the number of unusual responses according to the TTCT manual guidelines, some authors found that originality may be different for each specific culture. Should be considered for research in large populations, allowing the establishment of scales adapted to the study population. In this study, we have focused on creativity limited to assessing the creative potential that is expected to be most associated with creativity in children who have not yet had the opportunity to be evaluated from possible future achievements. The psychometric evaluation of creativity has been based on the divergent thinking tests (Runco \& Acar, 2012), but the multifaceted nature of creativity makes it necessary in future research to measure from different perspectives, where self-report measures, information collected from parents/teachers and real achievements can be included.

Simonton (2014) showed that creativity and psychopathology could share common traits. Moreover, at the extreme of greater psychopathology this relationship disappears (Abraham, 2015). Severe mental health disorders were refused in this study to avoid influencing outcomes. Although in future research the relationship between mental health pathologies clinical and subclinical, in 
children and creativity may have implications for explaining creativity.

\section{Acknowledgements}

We would like to give our thanks to Margaret Gatz (University of Southern California) for her collaboration in the revision of this article.

\section{Declaration of Conflicting Interest}

The authors declared no potential conflicts of interest with respect to the research, authorship, and/or publication of this article.

\section{References}

Abraham, A. (2015). Is There an Inverted-U Relationship between Creativity and Psychopathology? Frontiers in Psychology, 5, 13-15.

Abraham, A., Windmann, S., Siefen, R., Daum, I., \& Güntürkün, O. (2006). Creative Thinking in Adolescents with Attention Deficit Hyperactivity Disorder (ADHD). Child Neuropsychology, 12, 111-123. https://doi.org/10.1080/09297040500320691

American Psychiatric Association (2013). Diagnostic and Statistical Manual of Mental Disorders (DSM-5). Washington, D.C.: American Psychiatric Association. https://doi.org/10.1176/appi.books.9780890425596

Auerbach, J. G., Benjamin, J., Faroy, M., Geller, V., \& Ebstein, R. (2001). DRD4 Related to Infant Attention and Information Processing: A Developmental Link to ADHD? Psychiatric Genetics, 11, 31-35. https://doi.org/10.1097/00041444-200103000-00006

Barkley, R. A., Cook, E. H., Diamond, A., Zametkin, A., Thapar, A., \& Teeter, A. (2002). International Consensus Statement on ADHD. Clinical Child and Family Psychology Review, 5, 89-111. https://doi.org/10.1097/00004583-200212000-00001

Biederman, J., Petty, C. R., Clarke, A., Lomedico, A., \& Faraone, S. V. (2011). Predictors of Persistent ADHD: An 11-Year Follow-Up Study. Journal of Psychiatric Research, 45, 150-155. https://doi.org/10.1016/j.jpsychires.2010.06.009

Beghetto, R. A., \& Kaufman, J. C. (2007). Toward a Broader Conception of Creativity: A Case for Mini-C Creativity. Psychology of Aesthetics, Creativity, and the Arts, 1, 73-79. https://doi.org/10.1037/1931-3896.1.2.73

Carson, S. H., Peterson, J. B., \& Higgins, D. M. (2003). Decreased Latent Inhibition Is Associated with Increased Creative Achievement in High-Functioning Individuals. Journal of Personality and Social Psychology, 85, 499-606.

https://doi.org/10.1037/0022-3514.85.3.499

Castro, M. C., \& Martini, H. A. (2014). Statistical Power and Effect Size Calculating in g^Power: Complementary Analysis of Statistical Significance Testing and Its Application in Psychology. Salud \& Sociedad, 5, 210-224

Cordero, A., \& Calonge, I. (2000). Test Breve de Inteligencia de Kaufman (K-BIT). Adaptación Española. Madrid: Pearson [Kaufman, A. S., \& Kaufman, N. L. (1990). K-BIT: Kaufman brief intelligence test. American Guidance Service.]

Cohen, J. (1988). Statistical Power Analysis for the Behavioral Sciences. Hillsdale, NJ: Lawrence Erlbaum Associates.

Cramond, B. (1994a). Attention Deficit Hyperactivity Disorder and Creativity-What Is the Connection. Journal of Creative Behavior, 28, 193-210.

https://doi.org/10.1002/j.2162-6057.1994.tb01191.x

Cramond, B. (1994b). The Relationship between Attention-Deficit Hyperactivity Disord- 


\section{er and Creativity.}

Dietrich, A., \& Kanso, R. (2010). A Review of EEG, ERP, and Neuroimaging Studies of Creativity and Insight. Psychological Bulletin and Review, 136, 822-848. https://doi.org/10.1037/a0019749

Douglas, V. I., Barr, R. G., Desilets, J., \& Sherman, E. (1995). Do High Doses of Stimulants Impair Flexible Thinking in Attention-Deficit Hyperactivity Disorder? Journal of the American Academy of Child \& Adolescent Psychiatry, 34, 877-885. https://doi.org/10.1097/00004583-199507000-00011

El-Sayed, E., Larsson, J. O., Persson, H. E., Santosh, P. J., \& Rydelius, P. A. (2003). “Maturational Lag" Hypothesis of Attention Deficit Hyperactivity Disorder: An Update. Acta Pediatrics, 92, 776-784. https://doi.org/10.1111/j.1651-2227.2003.tb02531.x

Fugate, C. M., Zentall, S. S., \& Gentry, M. (2013). Creativity and Working Memory in Gifted Students with and without Characteristics of Attention Deficit Hyperactive Disorder Lifting the Mask. Gifted Child Quarterly, 57, 234-246. https://doi.org/10.1177/0016986213500069

Funk, J. B., Chessare, J. B., Weaver, M. T., \& Exley, A. R. (1993). Attention Deficit Hyperactivity Disorder, Creativity, and the Effects of Methylphenidate. Pediatrics, 91, 816-819.

González-Carpio, G., \& Serrano, J. P. (2016). Medication and Creativity in Attention Deficit Hyperactivity Disorder (ADHD). Psicothema, 28, 20-25.

Hansen, D. L., \& Hansen, E. H. (2006). Caught in a Balancing Act: Parents' Dilemmas Regarding Their ADHD Child's Treatment with Stimulant Medication. Qualitative Health Research, 16, 1267-1285. https://doi.org/10.1177/1049732306292543

Healey, D., \& Rucklidge, J. J. (2005). An Exploration into the Creative Abilities of Children with ADHD. Journal of Attention Disorders, 8, 88-95. https://doi.org/10.1177/1087054705277198

Healey, D., \& Rucklidge, J. J. (2006). An Investigation into the Psychosocial Functioning of Creative Children: The Impact of ADHD Symptomatology. Journal of Creative Behavior, 40, 243-264. https://doi.org/10.1002/j.2162-6057.2006.tb01276.x

Holbrook, J. R., Cuffe, S. P., Cai, B., Visser, S. N., Forthofer, M. S., Bottai, M., McKeown, R. E. et al. (2014). Persistence of Parent-Reported ADHD Symptoms from Childhood through Adolescence in a Community Sample. Journal of Attention Disorders, 20, 11-20. https://doi.org/10.1177/1087054714539997

Jauk, E., Benedek, M., \& Neubauer, A. C. (2014). The Road to Creative Achievement: A Latent Variable Model of Ability and Personality Predictors. European journal of personality, 28, 95-105. https://doi.org/10.1002/per.1941

Kim, K. H., Cramond, B., \& Bandalos, D. L. (2004). The Latent Structure and Measurement Invariance of Scores on the Torrance Tests of Creative Thinking-Figural. Educational and Psychological Measurement, 66, 459-477.

https://doi.org/10.1177/0013164405282456

Krumm, G., Lemos, V., \& Filippetti, V. (2014). Factor Structure of the Torrance Tests of Creative Thinking Figural Form B in Spanish-Speaking Children: Measuring Invariance across Gender. Creativity Research Journal, 26, 72-81.

https://doi.org/10.1080/10400419.2013.843908

Manzini, J. L. (2000). Helsinki Statement: Ethical Principles for Research Medicine about Human Subjects Acta Bioethica, 6, 321-334.

Mattfeld, A. T., Gabrieli, J. D., Biederman, J., Spencer, T., Brown, A., Kotte, A., Whitfield-Gabrieli, S. et al. (2014). Brain Differences between Persistent and Remitted Attention Deficit Hyperactivity Disorder. Brain, 137, 2423-2428. 
https://doi.org/10.1093/brain/awu137

Munafò, M. R., Yalcin, B., Willis-Owen, S. A., \& Flint, J. (2008). Association of the Dopamine D4 Receptor (DRD4) Gene and Approach-Related Personality Traits: Meta-Analysis and New Data. Biological Psychiatry, 63, 197-206.

https://doi.org/10.1016/j.biopsych.2007.04.006

Paek, S. H., Abdulla, A. M., \& Cramond, B. (2016). A Meta-Analysis of the Relationship between Three Common Psychopathologies-ADHD, Anxiety, and Depression-and Indicators of Little-C Creativity. Gifted Child Quarterly, 60, 117-133. https://doi.org/10.1177/0016986216630600

Polanczyk, G., de Lima, M. S., Horta, B. L., Biederman, J., \& Rohde, L. A. (2007). The Worldwide Prevalence of ADHD: A Systematic Review and Metaregression Analysis. The American Journal of Psychiatry, 164, 942-948.

https://doi.org/10.1176/ajp.2007.164.6.942

Pliszka, S. R. (2007). Pharmacologic Treatment of Attention-Deficit/Hyperactivity Disorder: Efficacy, Safety and Mechanisms of Action. Neuropsychology Review, 17, 61-72. https://doi.org/10.1007/s11065-006-9017-3

Plucker, J. A., Beghetto, R. A., \& Dow, G. T. (2004). Why Isn't Creativity More Important to Educational Psychologists? Potentials, Pitfalls, and Future Directions in Creativity Research. Educational Psychologist, 39, 83-96. https://doi.org/10.1207/s15326985ep3902 1

Pritchard, V. E., Healey, D., \& Neumann, E. (2006). Assessing Selective Attention in ADHD, Highly Creative, and Normal Young Children via Stroop Negative Priming Effects. In C. Fletcher-Flinn, \& G. Haberman (Eds.), Cognition and Language: Perspectives from New Zealand (pp. 207-224). Bowen Hills: Australian Academic Press.

Runco, M. A. (2007). To Understand Is to Create: An Epistemological Perspective on Human Nature and Personal Creativity. In R. Ruth (Ed.), Everyday Creativity and New Views of Human Nature: Psychological, Social, and Spiritual Perspectives (pp. 91-107). Washington: American Psychological Association. https://doi.org/10.1037/11595-004

Runco, M. A. (2014). Creativity: Theories and Themes: Research, Development, and Practice. New York: Academic Press.

Runco, M. A., \& Acar, S. (2012). Divergent Thinking as an Indicator of Creative Potential. Creativity Research Journal, 24, 66-75. https://doi.org/10.1080/10400419.2012.652929

Sahib, H. (2012) Qualitative Analysis of Creativity Used TTCT Test about Children with and without ADHD Tendency. Korean Society for Creativity Education, 12, 45-63. http://www.riss.kr/link?id=A60243750

Sang, B., Yu, J., Zhang, Z., \& Yu, J. (2002). A Comparative Study of the Creative Thinking and Academic Adaptivity of ADHD and Normal Children. Psychological Science, 25, 31-33.

Shaw, G. A., \& Brown, G. (1990). Laterality and Creativity Concomitants of Attention Problems. Developmental Neuropsychology, 6, 39-56. https://doi.org/10.1080/87565649009540448

Shaw, G. A., \& Brown, G. (1991). Laterality, Implicit Memory and Attention Disorder. Educational Studies, 17, 15-23. https://doi.org/10.1080/0305569910170102

Shaw, G., \& Brown, G. (1999). Arousal, Time Estimation, and Time Use in Attention-Disordered Children. Developmental Neuropsychology, 16, 227-242. https://doi.org/10.1207/S15326942DN1602 6

Shaw, P., Eckstrand, K., Sharp, W., Blumenthal, J., Lerch, J. P., Greenstein, D. E. E. A., Rapoport, J. L. et al. (2007). Attention-Deficit/Hyperactivity Disorder Is Characterized by a Delay in Cortical Maturation. Proceedings of the National Academy of Sciences, 
104, 19649-19654. https://doi.org/10.1073/pnas.0707741104

Simonton, D. K. (2004). Creativity in Science: Chance, Logic, Genius, and Zeitgeist. Cambridge: Cambridge University Press. https://doi.org/10.1017/CBO9781139165358

Simonton, D. K. (2014). More Method in the Mad-Genius Controversy: A Historiometric Study of 204 Historic Creators. Psychology of Aesthetics, Creativity, and the Arts, 8, 53-61. https://doi.org/10.1037/a0035367

Sonuga-Barke, E. J., \& Castellanos, F. X. (2007). Spontaneous Attentional Fluctuations in Impaired States and Pathological Conditions: A Neurobiological Hypothesis. Neuroscience \& Biobehavioral Reviews, 31, 977-986.

https://doi.org/10.1016/j.neubiorev.2007.02.005

Sternberg, R. J., Kaufman, J. C., \& Pretz, J. E. (2002). The Creativity Conundrum. New York: Psychology Press.

Sternberg, R. J., \& Kaufman, J. C. (2010). Constraints on Creativity: Obvious and Not So Obvious. In J. C. Kaufman, \& R. J. Sternberg (Eds.), The Cambridge Handbook of Creativity (pp. 467-482). New York: Cambridge University Press.

https://doi.org/10.1017/CBO9780511763205.029

Sternberg, R. J., \& Lubart, T. J. (1996). Investigating in Creativity. American Psychologist 7, 677-688. https://doi.org/10.1037/0003-066X.51.7.677

Sternberg, R. J. \& Lubart, T. J. (1999). The Concept of Creativity: Prospects and Paradigms. In R. J. Sternberg (Ed.), Handbook of Creativity (pp. 3-15). New York: Cambridge University Press.

Swanson, J. M. (2003) SNAP-IV Teacher and Parent Ratings Scale. In: F. Aykr (Ed.), Therapist's Guide to Learning and Attention Disorders (pp. 487-500). New York: Academic Press. https://doi.org/10.1016/B978-012256430-7/50022-3

Swanson, J. M., Cantwell, D., Lerner, M., McBurnett, K., \& Hanna, G. (1991). Effects of Stimulant Medication on Learning in Children with ADHD. Journal of Learning Disabilities, 24, 219-230. https://doi.org/10.1177/002221949102400406

Tannock, R., \& Schachar, R. (1992). Methylphenidate and Cognitive Perseveration in Hyperactive Children. Journal of Child Psychology and Psychiatry, 33, 1217-1228. https://doi.org/10.1111/j.1469-7610.1992.tb00940.x

Taylor, J. L. (2006). Attention Deficit Hyperactivity Disorder and Creative Potential of Children: A Multiple Case Study. Dissertation Abstracts International B: The Sciences and Engineering, 66, 4502.

Thomas, R., Sanders, S., Doust, J., Beller, E., \& Glasziou, P. (2015). Prevalence of Attention-Deficit/Hyperactivity Disorder: A Systematic Review and Meta-Analysis. Pediatrics, 135, e994-1001. https://doi.org/10.1542/peds.2014-3482

Thompson-Schill, S. L., Ramscar, M., \& Chrysikou, E. G. (2009). Cognition without Control When a Little Frontal Lobe Goes a Long Way. Current Directions in Psychological Science, 18, 259-263. https://doi.org/10.1111/j.1467-8721.2009.01648.x

Torrance, E. P. (1974). The Torrance Tests of Creative Thinking: Norms-Technical Manual. Princeton, NJ: Personal Press.

Torrance, E. P. (1990). Te Torrance Tests of Creative Thinking Norms-Technical Manual Figural (Streamlined) Forms A \& B. Bensenville, IL: Scholastic Testing Service.

Torrance, E. P. (1998). The Torrance Tests of Creative Thinking Norms-Technical Manual Figural (Streamlined) Forms A \& B. Bensenville, IL: Scholastic Testing Service.

Torrance E. P. (2008). Torrance Tests of Creative Thinking: Norms-Technical Manual, Figural (Streamlined) Forms A \& B. Bensenville, IL: Scholastic Testing Services.

Torrance, E. P., \& Safter, H. T. (1999). Making the Creative Leap beyond. Buffalo, NY: 
Creative Education Foundation Press.

Uddin, L. Q., Kelly, A. C., Biswal, B. B., Margulies, D. S., Shehzad, Z., Shaw, D., Milham, M. P. et al. (2008). Network Homogeneity Reveals Decreased Integrity of Default-Mode Network in ADHD. Journal of Neuroscience Methods, 169, 249-254. https://doi.org/10.1016/j.jneumeth.2007.11.031

White, H. A., \& Shah, P. (2006). Uninhibited Imaginations: Creativity in Adults with Attention-Deficit/Hyperactivity Disorder. Personality and Individual Differences, 40, 1121-1131. https://doi.org/10.1016/j.paid.2005.11.007

White, H. A., \& Shah, P. (2011). Creative Style and Achievement in Adults with Attention-Deficit/Hyperactivity Disorder. Personality and Individual Differences, 50, 673 677. https://doi.org/10.1016/j.paid.2010.12.015

Submit or recommend next manuscript to SCIRP and we will provide best service for you:

Accepting pre-submission inquiries through Email, Facebook, LinkedIn, Twitter, etc. A wide selection of journals (inclusive of 9 subjects, more than 200 journals)

Providing 24-hour high-quality service

User-friendly online submission system

Fair and swift peer-review system

Efficient typesetting and proofreading procedure

Display of the result of downloads and visits, as well as the number of cited articles

Maximum dissemination of your research work

Submit your manuscript at: http://papersubmission.scirp.org/

Or contact psych@scirp.org 